\title{
CORRECTIONS
}

\section{Are some diets "mass murder"?}

In the penultimate sentence of this Feature ( $B M J$

2014;349:g7654, doi:10.1136/bmj.g7654), the quotation from Nancy Harmon Jenkins contains a slight error. This should have read: "The food world is particularly prey to corruption [not 'consumption' as published], because so much money is made on food and so much depends on talk and especially the opinions of experts."

Cite this as: BMJ 2015;351:h4884

๑ BMJ Publishing Group Ltd 2015 